ISSN: 2238-8052

\title{
ESTRATÉGIAS, CONQUISTAS E PERMANÊNCIAS DO MLB NOS NÚCLEOS DA RMR: MECANISMOS DE TRANSFORMAÇÃO OU DE INTERMEDIAÇÃO COM O ESTADO?
}

\author{
MLB STRATEGIES, CONSEQUENCES AND PERMANENCIES IN THE RMR NUCLEUS: \\ MECHANISMS OF TRANSFORMATION OR INTERMEDIATION WITH THE STATE?
}

Cleiton Ferreira da SILVA ${ }^{1}$

Palavras-chave: Organização Intermediação Transformação Socioespacial

Keywords: Organization Intermediation Socio-spatial transformation

\section{R E S U M O}

Este artigo problematiza as políticas recentes de habitação popular, especialmente as que promoveram a participação dos movimentos sociais sem-teto, seja em conselhos, em reuniões, em mecanismos de diálogo com os órgãos públicos ou mesmo na consolidação de marcos legais como o Estatuto da Cidade (EO) e o Ministério das Cidades. Discute-se portanto, o avanço e o grau desta mesma participação, porém, questiona-se paralelamente, como vem ocorrendo as conquistas pelos movimentos, uma vez que houve a redefinição do potencial de luta, com a ascensão do mecanismo intermediador e do dialógico, em detrimento da ação direta. Para balizarmos este debate, são analisados cinco núcleos de ocupação e antigas ocupações do Movimento de Lutas nos Bairros, Vilas e Favelas (MLB) nas cidades de Recife e Jaboatão dos Guararapes, estado de Pernambuco, através do levantamento da historicidade de cada área, entrevistas e acompanhamento in loco das ações. Tenta-se esclarecer, portanto, as principais conquistas, permanências e, as dificuldades estratégicas-políticas que o movimento enfrenta, inviabilizando assim, conquistas verdadeiramente efetivas em meio a uma conjuntura de retrocessos e esfacelamento de conquistas históricas para os movimentos populares.

\section{A B S T R A C T}

This article discusses the recent policies of popular housing, especially those that promoted the participation of homeless social movements, be it in councils, meetings, mechanisms of dialogue with public agencies or even in the consolidation of legal frameworks such as the City Statute and the Ministry of Cities. We discuss, therefore, the progress and the degree of this same participation, but it is questioned in parallel, as the achievements of the movements have been occurring, since there was a redefinition of the potential of struggle, with the rise of the intermediary mechanism and the dialogical, to the detriment of direct action. In order to conclude this debate, five occupation nuclei and former occupations of the Movimento de Lutas nos Bairros, Vilas e Favelas (MLB) in the cities of Recife and Jaboatão dos Guararapes, Pernambuco State, are analyzed by surveying the historicity of each area, interviews and on-site monitoring of actions. The main achievements, permanencies, and strategic-political difficulties that the movement faces are thus avoided, thus making it impossible to achieve truly effective achievements amid a setback of setbacks and the shattering of historical achievements for popular movements.

\footnotetext{
${ }^{1}$ Doutor em Geografia pela UFPE. E-mail: cleitonf4@yahoo.com.br.
} 


\section{INTRODUÇÃO}

A história brasileira pós-ditadura é repleta de exemplos que expressam a vivacidade dos movimentos sociais pela Reforma Urbana. A busca incessante pela democratização dos espaços urbanos e a inserção das camadas populares em torno das políticas públicas são exemplos tácitos. Mais do que dar visibilidade às mazelas socioespaciais que acometem as cidades, os movimentos desempenham um fator importante, na medida em que propõem a democratização das políticas públicas habitacionais e a contraposição a um modelo hegemônico de privatização e "mercadificação" do espaço público.

Desde a volta da democracia no país, houve conquistas importantes como a inclusão na Constituição de capítulos sobre a questão urbana (1988), a aprovação do EC (2001), a criação do Ministério das Cidades (2003) e o surgimento de linhas de financiamento habitacionais que incluíam nas decisões, os movimentos sociais e as entidades de representação popular, como as associações de moradores.

Entretanto, da mesma maneira em que se criaram mecanismos democráticos e participativos, o Estado fez com que os movimentos se tornassem extremamente dependentes na conquista das políticas públicas, ou seja, linha de financiamento, doação de terreno para a construção, dotação de infra-estrutura necessária e auxílios financeiros como auxílio moradia, dependiam quase que exclusivamente de um processo de intermediação junto às instâncias. 0 fato é que houve uma supervalorização da intermediação com o Estado em detrimento de uma ação mais incisiva e transformadora (ruptura, ação direta etc.), ao mesmo tempo em que houve um arrefecimento de bandeiras históricas como a Reforma Urbana (fundiária e imobiliária).

Diante deste contexto supracitado, este artigo problematiza a atuação dos movimentos sociais, em especial o Movimento de Luta nos Bairros, Vilas e Favelas (MLB) em seus 05 núcleos de ocupação nas cidades de Recife e Jaboatão dos Guararapes, estado de Pernambuco, são eles: D. Hélder Câmara, Mulheres de Tejucupapo e Ruy Frazão em Recife e Mércia de Albuquerque I e II, ambos em Jaboatão. Tentou-se descrever, portanto, como ocorreu ou como vem ocorrendo o processo de negociação com o Estado (Governos federal, estadual e municipal), desde a inserção na linha de financiamento da Caixa Econômica Federal até a efetiva entrega das chaves. Paralelamente, são questionados os mecanismos estratégico-políticos adotados pelo movimento, as conquistas e os principais entraves para a consolidação de uma proposta verdadeiramente transformadora para as famílias e no embate com o Estado capitalista. 


\section{MOBILIZAÇÃO, LUTAS POPULARES E CONSTRUÇÃO DE MARCOS LEGAIS NAS CIDADES BRASILEIRAS}

0 processo de redemocratização e conquistas sociais no Brasil foi fruto de uma ampla mobilização popular, seja através da própria luta pela volta da democracia e garantia dos direitos sociais, seja por meio das chamadas ações mais pontuais das leis e regulamentações políticas, como a Constituição de 1988, a regulamentação do EC² em 2001, ou mesmo, a criação do Ministério das Cidades dois anos depois. Caracterizando-se, portanto, como marcos fundamentais de lutas para o reaparecimento e desenvolvimento do Movimento Nacional pela Reforma Urbana (MNRU). Logo, a luta pela efetivação das bases democráticas com o fim do Regime Militar, pelas eleições diretas, bem como pelas reivindicações contra as desigualdades socioespaciais, fincadas nos mais diversos segmentos do país, se consolidaram como algumas das ações do período pós-redemocratização ${ }^{3}$ e deram subsídios para a ascensão de diversos movimentos de caráter urbano.

Na década de 1990, por exemplo, os movimentos sociais urbanos difundiram-se, organizando passeatas, ocupações e caravanas, repercutindo decisivamente nas ações destes mesmos movimentos e desencadeando bases concretas para a elaboração da proposta de emenda popular à Constituição Federal acerca da política urbana. Para isso, institui-se o Fórum Nacional da Reforma Urbana (FNRU).

De início, regulamentou-se o capítulo de política urbana da Constituição Federal de 1988 (artigos 182 e 183); em seguida, a lei permitiu que as prefeituras pudessem contar com um instrumento progressista essencial de regulação do uso e ocupação do solo, e depois aprovou-se o EC, que se deu após 11 anos em tramitação, a partir da Lei Federal 10.257/01. Dentre os principais pontos destes marcos legais, podem ser destacados: a aplicação da função social da propriedade e da cidade; a legalização e urbanização que se referem à cidade ilegal; a promoção da gestão democrática, recuperação para a coletividade e a valorização imobiliária e o fortalecimento do planejamento com participação social (BRASIL/MCID, 2004).

As inovações verificadas no EC situam-se em três campos, os quais, divididos em conjuntos, possuem como objetivos: disciplinar o uso e ocupação do solo, a possibilidade de regularização fundiária e a participação popular nas decisões. 0 primeiro conjunto destina-se a coibir a prática da especulação imobiliária nos espaços urbanos, uma vez que o documento cria mecanismos para penalizar os proprietários de áreas "vazias" ou subutilizadas através do IPTU progressivo no tempo,

\footnotetext{
2 O Estatuto da Cidade representou um processo histórico para a retomada do Movimento Nacional pela Reforma Urbana, transformando-se na primeira lei de iniciativa popular através do recolhimento de mais de 1 milhão de assinaturas em todo país, desencadeando, logo em seguida, uma nova configuração da política urbana implantada até então no Brasil, com uma maior representatividade dos próprios movimentos sociais nas conferências das cidades, nos planos diretores municipais e na implantação de políticas públicas que reconhecessem a função social da propriedade e o direito à habitação.

${ }^{3}$ Alguns autores concordam que este período foi efervescente no surgimento de "novos sujeitos coletivos" com autonomia e resistência. 0 projeto político operário já não era mais visto, unicamente, como responsável pela transformação social e lutas populares (GOULART, 2011).
} 
estimulando a edificação e os parcelamentos compulsórios (ESTATUTO DA CIDADE, 2001). 0 segundo conjunto de instrumentos trata da regularização fundiária de áreas ocupadas e não tituladas da cidade; E por fim, o terceiro conjunto de instrumentos prevê a participação efetiva da população nas decisões que se relacionam à implantação e criação das políticas públicas de planejamento urbano.

Colocados em evidência os trâmites legais para a construção de cidades mais justas, era preciso criar a base institucional para que fossem implantadas as políticas propostas. Para isso, foi criado o Ministério das Cidades cuja ideia de criação data especificamente do período de campanha eleitoral à presidência em 1994 do então candidato pelo PT, Luís Inácio Lula da Silva (GRAZIA e RODRIGUES, 2003). A este Ministério caberia a formulação de ação planejadora, normativa e articuladora, bem como a elaboração de planos nacionais e a implementação de um sistema contínuo de dados e informações sobre a questão urbana e habitacional (BRASIL/MCID, 2004).

Oficialmente, o Ministério das Cidades foi implantado pelo Governo Lula, em 2003 (em seu primeiro ato como presidente da República) no intuito de consolidar as propostas elaboradas a partir do Projeto Moradia. 0 Ministério proporcionou também a discussão e implementação, em 2004, do Plano Nacional de Habitação (PlanHab) juntamente com o Conselho Nacional das Cidades, sendo então regulamentada pelo Fundo Nacional de Habitação de Interesse Social (FNHIS) e pelo Sistema Nacional de Habitação de Interesse Social (SNHIS) ${ }^{4}$.

Essas ações apontaram para a construção de um modelo diferente de planejamento do espaço urbano, colocando em evidência o combate à especulação imobiliária, o estímulo à participação popular e a politização das políticas públicas urbanas, como atesta Souza (2000):

O planejamento urbano alternativo preocupa-se antes com a melhor distribuição de investimentos públicos em infraestrutura pelo espaço da cidade, a fim de minimizar a segregação residencial e melhorar o acesso dos mais pobres a equipamentos de consumo coletivo (Ibidem, p. 278).

Durante o segundo mandato do presidente Luís Inácio Lula da Silva foi lançado dois programas fundamentais para a habitação: O Programa de Aceleração do Crescimento (PAC) em 2007 e o Programa Minha Casa Minha Vida (PMCMV)5 em 2009. O PAC da habitação destinou recurso específico para a habitação da ordem de R\$ 17 bilhões entre anos de 2007 e 2010, como parte integrante do eixo infraestrutura social e urbana, o programa evidenciou ainda a necessidade de universalização dos benefícios econômicos e sociais no país, para isso o plano reconhece que:

A melhoria das condições de habitabilidade das famílias moradoras em assentamentos precários deve ser entendida no contexto da garantia do direito à cidade. Muito mais do que uma política setorial, trata-se da garantia de qualidade ambiental, integração

\footnotetext{
4 Todavia, há críticas quando colocam que muitas das forças que lutaram pela Reforma Urbana ou puseram de pé, contrariando a cidade mercadoria, foram engolidos pela esfera institucional, possuindo cargos ou ao redor deles (MARICATO, 2015).

5 É preciso destacar que o caráter do programa não atraiu apenas as grandes incorporadoras e imobiliárias. Há a atração de pequenas e médias incorporadoras que não estavam associadas às grandes movimentações financeiras, mas que foram beneficiadas fundamentalmente pelas mudanças político-econômicas e pela segurança jurídica do programa.
} 
com a infraestrutura urbana instalada e acessibilidade ao mercado de trabalho e aos equipamentos públicos (BRASIL/MCID, 2010, p. 31).

Nesse sentido, o Programa previa a urbanização, regularização e integração dos assentamentos precários em diversas cidades brasileiras, através da parceria entre setor público e agente privado, tendo ainda como eixo de atuação a provisão de habitação de interesse social, a partir do apoio aos estados, Distrito Federal e municípios. Paralelamente, surgiram diversos programas que incentivaram a autogestão, ou seja, fruto de um amplo processo de reivindicação dos movimentos sociais, entre eles destacam-se: Operações Coletivas (programa que funcionou entre 2008 e 2011), Programa Crédito Solidário (PCS), Programa Minha Casa Minha Vida Entidades (PMCMVE)6, estes dois últimos foram substituídos por PCS em 2011 e FNHIS Entidades respectivamente (SILVA, 2012). Por outro lado, programas com o caráter essencialmente mercadológico também foram elaborados como o programa do governo intitulado Minha Casa Minha Vida (PMCMV) ${ }^{7}$ que nasceu da necessidade de estimular o desenvolvimento do setor da construção civil, bem como o estímulo ao crescimento do emprego e da economia no país em meio à crise mundial em $2008^{8}$.

Todavia, variadas críticas foram construídas e direcionadas aos programas implementados, especialmente porque eles sugerem a transferência de recursos públicos para a iniciativa privada, em especial, do setor da construção civil, tanto na urbanização de favelas e áreas precárias, como na construção de novas unidades habitacionais, ou seja, configurando como uma contraditória relação que se estabelece entre o setor público e o setor privado. Uma vez que o programa prevê a destinação de grande parcela do orçamento público em detrimento aos programas de incentivo à autogestão, como o PMCMVE. Esses fatores partem da justificativa da dificuldade do poder público, sobretudo municipal, na aplicação de recursos e a lentidão do PAC (SOUZA, 2009).

\footnotetext{
6 O PMCMV Entidades que seguia o mesmo modelo do Crédito Solidário, ou seja, 1. Entidades sem fins lucrativos apresentam o projeto à CAIXA que após análise, envia para o Ministério das Cidades que por sua vez faz a seleção, 2. A Caixa recebe a lista dos beneficiários, contrata a operação e acompanha a execução. Vale destacar que municípios com menos de 50 mil habitantes, cuja operação é através de agentes financeiros privados, são selecionadas pela Caixa. Por fim, o MCidades define e publica o volume dos recursos para cada agente, em determinada região (valores segundo as características da região). Porém, salienta-se que muitos programas estão praticamente suspensos.

7 Lançado em março de 2009 o programa previa a construção de 1 milhão de moradias, a partir do investimento de R\$ 34 bilhões. Para isso, o governo barateou as taxas de juros em financiamentos habitacionais e dos seguros, promoveu a criação de um Fundo Garantidor de Habitação (FGHAB), desenvolveu os incentivos fiscais para a produção de moradias para a baixa renda, além de reduzir os prazos e as custas cartoriais. A partir dessas ações, o governo bateu a meta de acordo com os dados do ano de 2010 divulgados pela Caixa Econômica Federal (BRASIL/MCID, 2010). E desencadeou variadas modificações no que tange as políticas públicas de habitação, desde o aumento dos investimentos na área de habitação, a priorização das famílias de baixa renda, a redução das taxas de juros, até o incentivo de regulamentação jurídica com certa rapidez ao processo. Isso, levando em consideração os subsídios parciais para as famílias que figuram entre 3 e 6 salários mínimos, enquanto as famílias que figuram no patamar de baixa renda, isto é, entre 1 e 3 salários mínimos, teriam o subsídio quase total.

8 De acordo com Fix (2011): Tanto o BNH como MCMV tratam a habitação como mercadoria a ser produzida em moldes capitalistas. No MCMV, no entanto, os subsídios diretos ao comprador podem ser vistos como um reconhecimento de que a habitação é um direito. Esse reconhecimento do direito tem caráter ambíguo, uma vez que justifica a injeção de recursos públicos em um sistema que, de resto, tem lógica privatista na definição dos espaços, inteiramente formulados segundo os critérios de um empreendimento imobiliário (FIX, 2011, p. 145).
} 
Paralelamente, o programa PMCMV, suplantou o Plano Nacional de Habitação (PlanHab), pois houve um direcionamento da política habitacional para atender especificamente ao setor da construção civil (como atesta o PMCMV) que definem os projetos e locais a serem construídos, reservando ao poder público apenas a responsabilidade de aprovação dos projetos, desencadeando, segundo Souza (2009) em um papel de refém do poder público, através de uma forma predatória e fragmentada de expansão urbana, promovida pela iniciativa privada. Nesse sentido, a facilidade de financiamento pelo BNDES para as empresas que solicitam empréstimos para construção de habitações, nas proximidades destas mesmas empresas, bem como a redução dos encargos sobre os lucros facilitaram significativamente a participação e o aumento dos lucros das empresas de construção civil. Além disso, as construções promovidas pelas empreiteiras, muitas vezes, são direcionadas para famílias que ganham entre 3 e 5 salários mínimos e não para atender as famílias inseridas no patamar de até 3 salários.

Portanto, o caráter de uma habitação popular no Brasil ganha contornos difusos e privatistas, ao passo que a condição ideológica de conquista da habitação não se efetiva pelo direito essencialmente, mas introjetado pela busca frenética de capitais e sua acumulação a partir de um bem essencial, incorporando áreas periféricas ausentes de mínimas condições de estrutura, funcionando como nichos para as incorporadoras (SILVA, 2016). Por outro lado, a conquista da moradia, na visão de muitos movimentos sem-teto, se baseou essencialmente pela via institucional, através dos programas e projetos de moradia financiados pelo Governo Federal, causando uma equação pouco progressista e com reduzidas perspectivas de mudanças profundas no Status Quo. Diante de um cenário de incertezas políticas e suspensão de construção de novas unidades habitacionais, especialmente destinadas aos movimentos populares, fica a dúvida quanto ao futuro das reivindicações e ao processo de reorganização da base para a consolidação de políticas duradouras e efetivamente democráticas 9.

\section{LUTA PEla MORAdia POPUlar: A ATUAÇÃO DO MLB NAS CIDADES DE RECIFE E JABOATÃO DOS GUARARAPES-PE}

Para que as ações do MLB se consolidem do ponto de vista prático, o movimento concentra-se em áreas pobres das cidades brasileiras, organizando a população em torno da conquista da moradia e

\footnotetext{
${ }^{9}$ A aprovação do projeto para a construção de milhares de moradias populares através do PMCMVE, foi sancionado em maio de 2016, como um dos últimos atos da presidente Dilma Rousseff (PT) antes do afastamento de 180 dias para a discussão do impeachment. Porém, foi vetado dias depois pelo então ministro das Cidades Bruno Araújo (PSDB), que alegou falta de verba para execução da obra, suspendendo a construção de 11.250 unidades. Ver em: shttp://www1.folha.uol.com.br/poder/2016/05/1772207-ministro-revoga-construcao-de-11250-unidades-do-minha-casa$\underline{\text { minha-vida.shtml }>}$
} 
dos direitos sociais a ela vinculados, tendo como orientação de primeira ordem a luta pela reforma urbana e pelo socialismo, portanto, elementos essenciais à construção de territorialidades diferentes.

Desde sua criação em 1999, o MLB atua e impulsiona sua luta em defesa da Reforma Urbana ${ }^{10}$, através das ocupações de prédios, terrenos abandonados e/ou subutilizados o que acontece na tentativa de exigir dos órgãos públicos a construção de moradias populares e de rompimento com a especulação imobiliária. Na busca pela mudança da realidade, é fundamental considerar todo o processo estratégico que desencadeia a ocupação, desde os elementos da organização, mobilização até sua efetiva execução, uma vez que ela funciona como um ato de resistência ao poder vigente estabelecido, além disso, as estratégias políticas após a ocupação promove, entre as famílias, o espírito de coletividade, a compreensão das contradições sociais no país e a importância de lutar pela reforma urbana.

Na maioria dos casos, em decorrência das mudanças recentes verificadas nas políticas habitacionais, é possível encaminhar, na modalidade de negociação: a regularização do imóvel ocupado; o projeto arquitetônico; a destinação de verbas para as obras; a inclusão nos programas sociais e de financiamento do governo; a discussão da implementação da infraestrutura necessária. Além disso, pode ocorrer o acompanhamento sistemático pelo MLB das ações do Estado desenvolvidas nas ocupações.

Entretanto, o processo de diálogo nem sempre funciona, diante da necessidade das famílias, resultando, muitas vezes, numa morosidade excessiva dos agentes públicos, provocando a atuação mais efusiva do movimento através de passeatas, ocupação de prefeituras, panfletagem, organização de barricadas e bloqueio de vias, reuniões, entre outras formas de reivindicação.

Duas cidades da Região Metropolitana do Recife11 (nordeste do Brasil) trazem algumas experiências das ocupações realizadas pelo MLB e que promoveram conquistas de centenas de casas

\footnotetext{
100 movimento sintetiza a apresentação do movimento no site oficial da seguinte forma: O Movimento de Luta nos Bairros, Vilas e Favelas (MLB) é um movimento social nacional que luta pela reforma urbana e pelo direito humano de morar dignamente. Somos um movimento formado por milhares de famílias sem-teto de todo o país vítimas da ação predatória da especulação fundiária e imobiliária. Acreditamos que a reforma urbana é um meio, um instrumento; ela faz parte da luta maior da classe trabalhadora para construir uma sociedade diferente, com igualdade, dignidade e direitos para todos: a sociedade socialista. Para o MLB, a luta pela moradia é o motor principal da luta pela reforma urbana, pois através dela conseguimos mobilizar milhares de pessoas, pressionar os governos e chamar a atenção para os problemas enfrentados pelo povo pobre nas grandes cidades. Nesse sentido, tem importância fundamental a organização e realização das ocupações. A ocupação educa o povo para a necessidade de lutar organizado e desenvolve o espírito de trabalho coletivo. Ocupar é um ato de rebeldia, de confronto com a ordem estabelecida, de questionamento à sagrada propriedade privada capitalista. Logo, enquanto morar dignamente for um privilégio, ocupar é um dever! (MLB, 2017, s/p).

11 Recife é considerada a capital do estado de Pernambuco e, a maior do ponto de vista populacional, com 1.537,704 habitantes, de acordo com o censo de 2010 (IBGE, 2016), a cidade limita-se com os municípios de Jaboatão dos Guararapes, São Lourenço da Mata, Camaragibe, Paulista e Olinda. Como outras capitais do país, ela reflete o cenário de desigualdade e contradições no espaço urbano, desencadeando conflitos e disputas políticas. De acordo com a Fundação João Pinheiro (2013), o nordeste figura-se entre as regiões do país com um elevado déficit habitacional absoluto, com 1,844 milhão de moradias em 2013, bem como quando se avalia as habitações precárias com 31,0\% do peso do déficit, ou seja, o maior índice entre todas as regiões pesquisadas. Já no quadro da RMR o índice absoluto chega a 100.870 habitações, sendo 97.643 urbanas e 3.227 em áreas rurais. De acordo com o levantamento da ONG Habitat para a Humanidade Brasil, o déficit de moradias no Recife em 2015 era de aproximadamente 62.687 residências (SCHIAFFARINO, 2015). 0 município de Jaboatão localiza-se no litoral do estado de Pernambuco e possui uma extensão territorial de $256 \mathrm{~km}^{2}$, limita-se ao Norte com Recife e
} 
populares para as famílias. Para compreender as diferentes experiências do movimento nas cidades de Recife e Jaboatão dos Guararapes, nos detivemos em analisar 05 núcleos de ocupação: D. Hélder Câmara, Mulheres de Tejucupapo e Ruy Frazão em Recife e Mércia de Albuquerque I e II, ambos em Jaboatão, que possuem particularidades e características diferentes, relacionadas ao processo organizativo, à intermediação com as instâncias públicas e, ao mesmo tempo, de consolidação e entrega das moradias (em alguns dos núcleos). A ideia é problematizar criticamente suas ações e contextualizar a importância da mobilização popular na construção de cidades mais democráticas e de políticas efetivamente públicas.

O núcleo Dom Hélder Câmara é fruto de um intenso processo de mobilização e, fundamentalmente de resistência desencadeadas ao longo de vários anos pelo movimento, em comunhão com as famílias no bairro da Iputinga, Zona Oeste do Recife. Considerado um dos núcleos do MLB na RMR que mais obteve celeridade, quanto à construção, o conjunto em questão possui 200 moradias que foram edificadas em regime de mutirão autogestionado, através da antiga linha de crédito que atendia a sociedade organizada (sindicatos, movimentos sociais, cooperativas, etc.), denominada Crédito Solidário12.

O núcleo Mulheres de Tejucupapo surge em novembro de 2007 também no bairro da Iputinga, em Recife. Inicialmente com um número aproximado de 135 famílias, que se dividiam da seguinte forma: 15 famílias que não se encaixaram nos critérios restritivos colocados pelo PCS na época ao núcleo D. Hélder Câmara e, as outras 120 famílias, oriundas do bairro supracitado e outros circunvizinhos, que conheceram a proposta do MLB e a ideia de ocupar um imóvel através de amigos, vizinhos e parentes.

Em janeiro de 2012 é assinado o contrato pelas famílias de construção de 272 apartamentos em estilo "caixão" em quatro andares (térreo, primeiro, segundo e terceiro) com $35 \mathrm{~m}^{2}$ cada, uma pequena área de lazer comum para os moradores e, a dotação da estrutura básica necessária (água, luz, ruas principais). 0 prazo de entrega ficou estabelecido inicialmente para 2014, entretanto, as obras atualmente estão paralisadas, possuindo apenas $40 \%$ de conclusão (Figura 01). A companhia de

São Lourenço da Mata, ao Sul com o Cabo de Santo Agostinho, a Leste com o Oceano Atlântico a Oeste com Moreno. Configurase como um dos maiores da RMR, com uma população total de 644.620 habitantes em 2010 e uma população estimada para o ano de 2015 de 686.122 hab. (IBGE, 2016). Apesar de ser o segundo município em arrecadação, ficando atrás da capital do estado, os índices de desigualdade materializam-se em vários setores. No que se refere aos dados sobre déficit habitacional de 2008, por exemplo, a Fundação João Pinheiro calculou que o déficit era de 20.384 habitações, correspondendo a 10,5\% dos domicílios do município (FJP, 2010).

12 Programa desenvolvido pelo governo federal que permitia com que famílias agrupadas em uma cooperativa, associação ou entidade privada sem fins lucrativos, utilizassem o Fundo de Desenvolvimento Social (FDS) para compra ou reforma da casa própria com os seguintes agentes envolvidos: 1. Caixa Econômica Federal, operava financeiramente, 2. Ministério das Cidades geria as aplicações, 3. Entidades representativas que eram os agentes organizadores, 4. Poder público, que integrava-se como agente fomentador e, 5. Beneficiários que eram as respectivas famílias. Todo o processo era feito em regime de mutirão ou auto-ajuda através das entidades que também realizavam a administração direta, entrega do projeto à Caixa e do projeto técnico social. 0 Programa financiava 95\% do valor total do investimento, enquanto as famílias contribuíam com 5\%, podendo ser deduzido durante a execução da obra. Atualmente este programa foi substituído pelo Programa Minha Casa Minha Vida Entidades (PMCMVE). Ver mais detalhes sobre o Crédito Solidário em: <http://www.unmp.org.br/ index.php?option=com content\&view=article\&id=189:programa-credito-solidario\&catid=64:credito-s $>$ 
habitação do estado alega a falta de recursos federais para o término, todavia, mesmo com este imbróglio, o MLB mantém as reuniões semanais para discutir novos informes e direcionar as famílias para mobilizações de retomada da construção e entrega das moradias.

Figura 01: Situação atual do Conjunto Habitacional Mulheres de Tejucupapo, 2016.

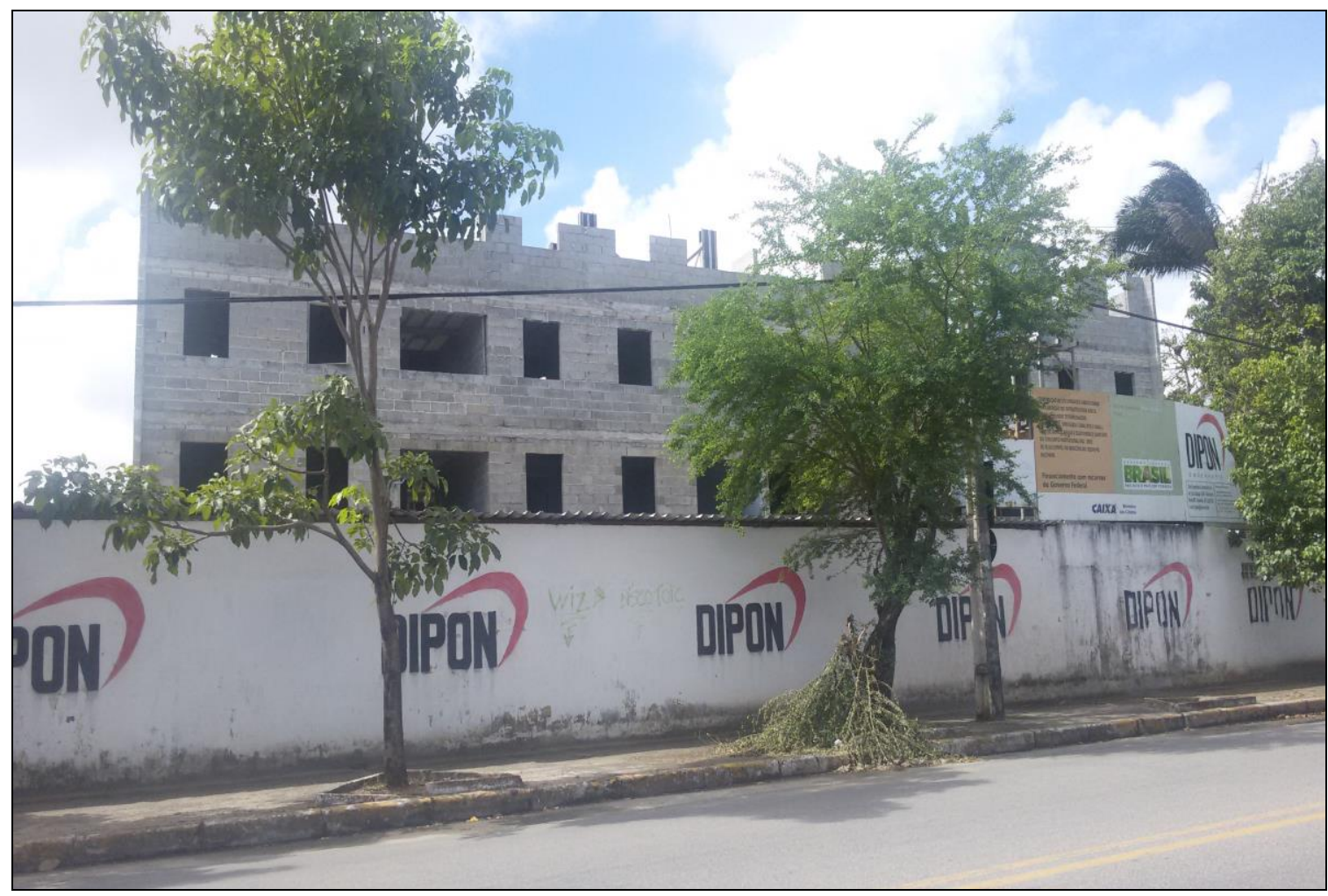

Fonte: 0 autor (2016).

No núcleo Ruy Frazão, o MLB realizou a ocupação com aproximadamente 300 famílias em 31 de janeiro de 2012 em um terreno pertencente à Universidade Federal de Pernambuco (UFPE). As demais foram sendo incorporadas à medida que a ocupação tomava força e corpo. Vários ocupantes possuíam trajetórias de vida bastante similares: donas de casa, desempregados, trabalhadores que viviam de bicos e moradores de áreas precárias da cidade que não possuíam a casa própria. Em abril de 2012 é assinada, no auditório do Centro de Tecnologia da UFPE, a carta de anuência que destinaria um terreno 2,4 hectares no bairro de Afogados (área central da cidade) para as 350 famílias cadastradas no núcleo Ruy Frazão, em articulação com a própria Universidade e o Ministério Público da União.

A aprovação do projeto para a construção das 350 moradias populares através do PMCMVE, foi sancionado em maio de 2016, como um dos últimos atos da presidente Dilma Rousseff (PT) antes do afastamento de 180 dias, porém foi suspensa com a chegada do atual governo. A ocupação que desencadeou nos atuais núcleos Mércia de Albuquerque I e II é resultante de um intenso processo de 
mobilização que durou cerca de 13 anos, até a conquista das primeiras moradias pelas famílias. Data especificamente de abril de 2003 a ocupação nas proximidades do bairro de Dom Hélder, Jaboatão dos Guararapes, Região Metropolitana do Recife.

O local escolhido na época, nas proximidades da Lagoa do Náutico, possui imensas terras sem qualquer função social, áreas de difícil acesso e alagadiças, principalmente em épocas de fortes chuvas. Porém, utilizado para a criminalidade, para o abandono de carcaça de carros roubados, enfim, um local que sequer entra no mapa do poder público na hora de qualquer intervenção político-social. Esta realidade é tão atual que diversos habitantes que margeiam a lagoa sofrem com a falta de saneamento, postos de saúde, transporte e área de lazer até hoje.

Após a conquista do terreno em outra área, as mobilizações ocorreram sistematicamente, seja para a regularização do imóvel, para a inserção das famílias em uma política de construção habitacional do governo federal (neste caso no Programa Minha Casa Minha Vida13) ou mesmo para pressionar na aceleração das obras. Vale salientar que todo o processo de conquista aconteceu com extrema morosidade por parte do poder público, fato que levou 13 anos para que as moradias de um dos núcleos (Mércia I) ficassem efetivamente prontas. Em dezembro de 2015, as moradias do núcleo Mércia I são entregues (Figuras 02 e 03).

Figuras 02 e 03. Conjunto Habitacional Mércia de Albuquerque I concluído

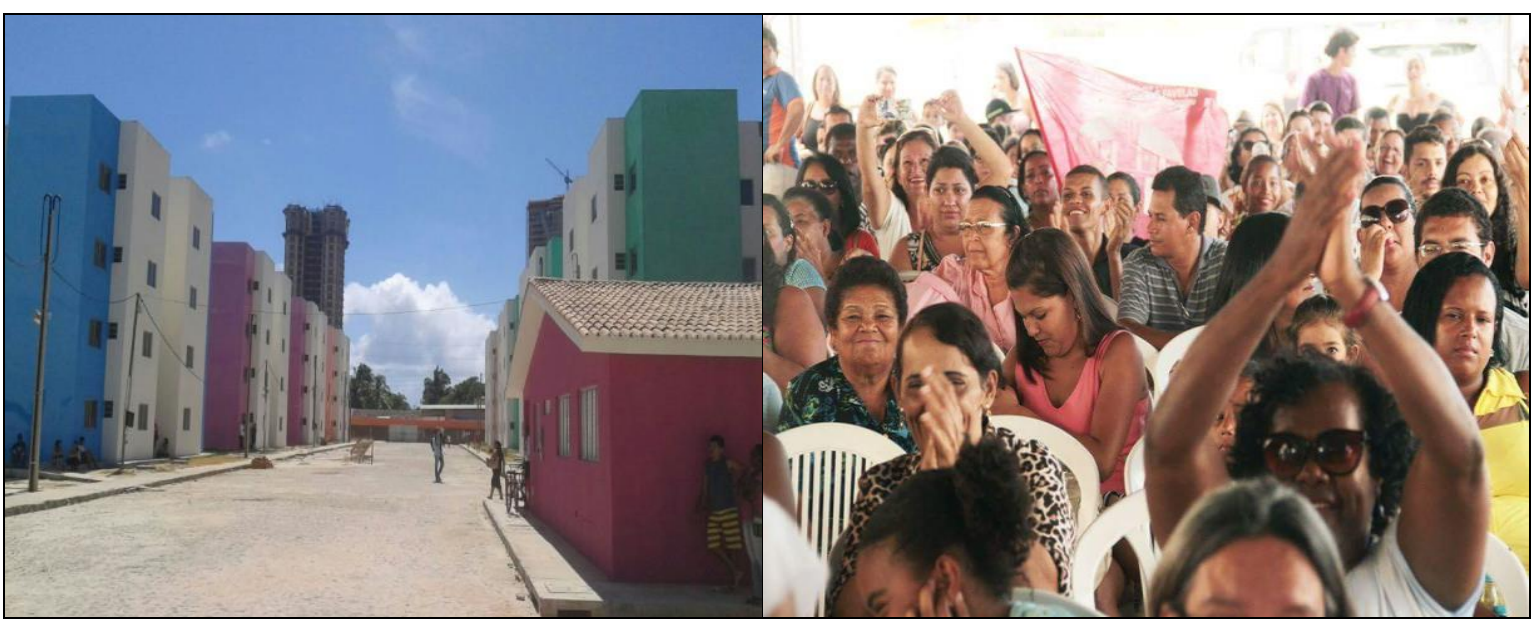

Fonte: Acervo fotográfico do MLB (2015).

\footnotetext{
${ }^{13}$ Há uma modalidade que opera com recursos do Fundo de Arrendamento Residencial (FAR) oriundos do Orçamento Geral da União (OGU) para atender a construção de unidades habitacionais e minimizar o déficit habitacional de famílias com renda de até $\mathrm{R} \$ 1.600,00$, considerando a estimativa da Pesquisa Nacional por Amostra de Domicílios (PNAD), de 2008. A inscrição é feita pelo poder público (estados e municípios) que, encaminha a proposta de compra de terrenos e produção ou requalificação para a Caixa. Após a análise e aprovação do projeto, a Caixa contrata a operação e acompanha a execução da obra. Ver detalhes em: shttp://www.caixa.gov.br/poder-publico/programas-uniao/habitacao/minha-casa-minhavida/Paginas/default.aspx $>$.
} 
Trata-se de um conjunto habitacional com 256 apartamentos com $41 \mathrm{~m}^{2}$ cada, construídos em prédio tipo "caixão" em quatro andares. 0 conjunto possui ainda quadra poliesportiva e um salão de festas para os moradores. Em parceria com o poder público municipal, o acesso ao conjunto e o saneamento básico necessário foram garantidos. Também foram articuladas parcerias com universidades para a realização do diagnóstico das famílias do núcleo, mecanismo exigido pela Caixa para a liberação de valores. O Núcleo Mércia de Albuquerque II está em fase de finalização, sob a mesma política de cooperação com o poder público local. Portanto, a análise destes núcleos e a trajetória de mobilização e intermediação dos movimentos (neste caso o MLB), demonstram conquistas essenciais, mas explicitam algumas permanências, do ponto de vista político-estratégico, elementos estes que inviabilizam uma verdadeira reforma urbana/fundiária.

\section{ESTRATÉGIAS E AÇÃo DIRETA DO MLB NOS NÚCleOS DE OCUPAÇão: AÇÃo DE TRANSFORMAÇÃO OU DE INTERMEDIAÇÃO COM O ESTADO?}

0 resultado do estudo mostrou o quanto as ações pedagógicas dos movimentos são limitadas em alguns casos, quando se considera o grau de trabalho e coesão das famílias, pois a quantidade de membros pertencentes ao movimento reduz significativamente após a entrega das moradias, por outro lado, a cronologia é um fator desestimulante, porque quanto maior o tempo de entrega das moradias, maior o processo de desmobilização e descrédito no movimento e suas ações, refletindo também no número de desistências e no arrefecimento da participação nas reuniões e nos atos organizados, fruto principalmente da leniência do Estado. De fato, o tempo longo da ação do Estado em áreas pobres é resultante das descontinuidades políticas e técnicas, um fator que desestimula as negociações.

Muitas das famílias não sentem interesse em construir ações coletivas no conjunto habitacional onde residem depois de diversas lutas travadas, sejam para a construção da associação de moradores ou mesmo em mobilizações posteriores que possam surgir, como: conquista de calçamento de ruas, construção de creches, escolas ou a implantação da coleta seletiva, paralelamente, a dimensão da propriedade individual ascende em contraposição à dimensão coletiva (SILVA, 2012). Reconhecem, portanto, a importância da luta e mobilização, contudo, minimizam o poder da práxis. É óbvio que a contraposição dos movimentos em relação à "cultura" dominante é extremamente desigual: meios de comunicação, padrões de vida, comportamentos e valores morais hegemônicos funcionam, muitas vezes, como mecanismos que desarticulam, promovem o individualismo, isto é, a introjeção do "opressor", nas palavras de Freire (1987) ${ }^{14}$.

\footnotetext{
14 Porém, o próprio autor (1987) estabelece mecanismos que possam construir a práxis libertadora, ou seja, a reflexão, a criticidade, a sua condição enquanto ser pensante que possa conduzir à prática da liberdade: "Somente quando os oprimidos descobrem, nitidamente, o opressor, e se engajam na luta organizada pela sua libertação, começam a crer em si mesmos,
} 
Muitas vezes, as práticas das famílias terminam sendo caracterizadas ou condicionadas meramente pela busca da casa, que de fato é o objetivo primordial do movimento e das famílias semteto. Mas até a sua conquista efetiva, há uma série de questionamentos que poderiam ser discutidos em torno desse contexto: a conjuntura política, social e econômica do país, que exclui um elevado número de famílias na conquista da casa; a necessidade pela reforma urbana; a concentração de renda e a estrutura fundiária no país, que resultam em espaços mais segregados e contraditórios; a privatização dos espaços públicos como praças, parques e áreas verdes; e, fundamentalmente, a importância na busca de uma práxis libertadora, ou seja, a conquista efetiva da produção social do habitat, colocando a dimensão humana no centro de todo o processo, fortalecendo, assim, os excluídos, a comunidade e as famílias (DE LA MORA, 2010).

Certamente que estes assuntos são tratados em todo o processo organizativo, isto é, desde as primeiras reuniões antes da ocupação até a cerimônia de entrega das moradias, todavia, as informações devem surgir através da reflexão e da práxis em cada uma das famílias inseridas neste contexto e não de forma pragmática. Não transformando, a própria mobilização, num elemento também precário. A assinatura da ata de presença nas reuniões, assembleias e mobilizações não podem ser mais importantes do que o efetivo comparecimento das famílias aos eventos promovidos pelos movimentos (mobilizações e atos). Isso parece ser um dos pontos que requer atenção, uma vez que a mobilização tem caráter "espontâneo" e depende do grau de consciência de cada família. A participação não deve ocorrer simples e unicamente por estar vinculada aos movimentos na conquista da moradia.

O foco é, portanto, a necessidade da luta pela casa, criando mecanismos críticos e reflexivos antes e após a entrega das moradias, colocando em evidência a importância da participação nessas atividades, logo, os movimentos precisam compreender, que os aspectos da mobilização exigem uma permanente busca pela liberdade, isto é, a liberdade como condição essencial de existência e garantia dos direitos deve ser uma luta incessante, cujos objetivos são a superação da velha situação posta pelos opressores. Porque a entrega da casa pela casa pode causar duas contradições: 1. Tornar o movimento "relações públicas" ou mero negociador entre famílias e Estado e 2. Inserir as famílias (apenas) a um modelo de consumo vigente no país que beneficia aos grupos imobiliários.

Outro ponto importante é o caráter intermediador que os movimentos possuem. De fato, sem a interlocução junto aos órgãos do Estado, não haveria avanços quanto à regularização do imóvel, à inserção aos programas de construção das moradias, à construção dos projetos sociais, porque o

superando, assim, sua "conivência" com o regime opressor. Se esta descoberta não pode ser feita em nível puramente intelectual, mas da ação, o que nos parece fundamental, é que esta não se cinja a mero ativismo, mas esteja associada a sério empenho de reflexão, para que seja práxis. [...] 0 que pode e deve variar, em função das condições históricas, em função do nível de percepção da realidade que tenham os oprimidos é o conteúdo do diálogo. Substituí-lo pelo anti-diálogo, pela sloganização, pela verticalidade, pelos comunicados, é pretender a libertação dos oprimidos pela "domesticação". Pretender a libertação deles sem a sua reflexão no ato desta libertação é transformá-los em objeto que devesse salvar de um incêndio. È fazê-los cair no engodo populista e transformá-los em massa de manobra" (FREIRE,1987, p.108). 
Estado, no capitalismo, não cria mecanismos efetivos de independência dos movimentos sociais do ponto de vista político-social, uma vez que restringe políticas autônomas efetivas, todavia, ele não deve ser encarado com uma postura de aversão ou mesmo de negação efetiva. Souza (2010, p. 25) discute o pensamento autonomista de Cornelius Castoriadis e sinaliza que é preciso diferenciar o Estado sob a perspectiva "estadófobas", ou seja, que nega ou que é averso ao mesmo, da perspectiva "estadocrítico", isto é, através da crítica do Estado capitalista ou além disso, a ideia do Estado em geral. Encara-se, portanto, as instâncias estatais como o resultado da correlação de forças existentes na sociedade, marcadas por conflitos e que oferecem pontos vulneráveis e potencialidades a serem explorados eventualmente pelos movimentos sociais: brechas legais, instâncias participativas oficiais, recursos públicos (SOUZA, 2010).

Dessa forma, o diálogo com as instâncias governamentais, mesmo funcionando como ferramenta estratégica e política importante para as conquistas das famílias, às vezes, atua como limitador de ações dos movimentos, fazendo com que as questões meramente burocráticas sejam mais importantes que a combatividade e a organização das famílias em torno da transformação da sociedade. Um exemplo disso foi a normativa do Ministério das Cidades que instituiu como précondição a criação de associações (administradas pelas organizações populares) que geria a obra do programa Crédito Solidário, ou seja, a associação assumia o papel de mediador do Estado, exigindo que se cumprissem as regras do programa (participação no mutirão, pagamento de taxas da CEF, etc.), com risco de exclusão das famílias.

Para Maricato (2015, p. 32), o "modo petista de governar", através de gestões inovadoras, autodeterminadas "democráticas populares" e com a participação social recuou, ao passo que a cidade corporativa e a aplicação de recursos na iniciativa privada, por parte do Estado, tiveram um salto significativo. Atrela-se a isso, o esquecimento de bandeiras históricas como a Reforma Urbana e o rompimento da estrutura fundiária vigente. Rui Braga (2015, p. 202) sinaliza que este modelo de governabilidade foi introjetado também em setores sindicais ${ }^{15}$, sobretudo após a eleição de Lula em $2002^{16}$.

Paralelamente, a morosidade no encaminhamento das obras de construção das moradias (regularização do imóvel, aprovação do projeto, inserção em programas do governo) e,

\footnotetext{
15 A partir do levantamento do número anual de greves no Brasil, compilado pelo DIEESE entre os anos de 1992 e 2008 , Cardoso (2016) observou uma redução gradativa das greves, especialmente a partir dos anos 2000, resultantes do amortecimento da ação sindical provocadas pela precarização da classe trabalhadora e pela substituição do trabalho vivo pelo trabalho morto, além disso, houve a permanência da estrutura sindical corporativista e das opções políticas de liderança da CUT, que direcionou seu apoio à política do governo e ao posicionamento acrítico às mudanças no mundo laboral, já no primeiro mandato de Lula.

16 "No entanto esses dirigentes foram absorvidos pelo aparelho de Estado e pelos fundos de pensão, transformando-se em verdadeiros administradores do investimento capitalista no país. Ou seja, eles não representam mais os interesses históricos dos trabalhadores, mas, sim, os interesses particulares de uma burocracia sindical que rapidamente está se transformando em uma burguesia de Estado. Esse tipo de "transformismo" social tende a afastar as antigas lideranças sindicais absorvidas pelas funções administrativas das demandas provenientes do ativismo de bases formadas, sobretudo, pelo proletariado precarizado. Eis o campo de tensão entre o regime de acumulação e o modo de regulação" (BRAGA, p. 202, 2015).
} 
consequentemente a sua entrega podem acumular vários anos e, em algumas situações, mais de uma década, dependendo da conjuntura político-econômica dos órgãos públicos (municipal, estadual e federal) e do tipo de programa em que foi incluso o respectivo núcleo. Essa demora vem provocando uma série de desgastes, referentes à coesão das famílias. Muitas delas se afastam das atividades por não compreenderem a importância de permanecerem lutando e não acreditarem no potencial que as mobilizações possuem, bem como na possibilidade efetiva das conquistas.

Se a dimensão econômica (moradia) é uma urgência e ganhou uma significação ímpar para as famílias, o aspecto político (transformação sociopolítica) não pode ser subestimado; Afinal, essas duas dimensões devem pautar a atuação dos movimentos sociais. Buscar a solução das questões pontuais sem romper com o modelo que promove as contradições é retroalimentar o estado das coisas. Para isso, a ação dos movimentos é fundamental na construção de uma alternativa política e teórica:

Para tal, tem-se no entanto de encontrar maneiras de reconhecer a relevância das múltiplas identificações (baseadas na classe, no gênero, no local, na cultura etc.) existentes no seio das populações, os vestígios da história e da tradição que advêm das formas pelas quais essas identificações se constituíram em resposta a incursões capitalistas na medida em que as pessoas se vêem como seres sociais dotados de qualidades e aspirações distintivas e muitas vezes contraditórias. Se isso não acontecer, corre-se o risco de recriar as lacunas do relato que Marx fez da acumulação primitiva e deixar de perceber o potencial criativo que reside naquilo que alguns consideram desdenhosamente relações sociais e sistemas de produção "tradicionais" e não-capitalistas. Tem-se de encontrar uma maneira, tanto teórica como politicamente, de ir além do amorfo conceito de "multidão" sem cair na armadilha do "minha comunidade, meu local ou meu grupo social acima de tudo" (HARVEY, 2005, p. 146).

É inegável a importância das ações insurgentes dos movimentos na democratização do espaço urbano, mas é preciso avançar para conquistar territórios verdadeiramente transformadores; romper com a dimensão da minimização do sofrimento através de políticas e ações pontuais; conquistar verdadeiramente os direitos civis (direito à liberdade, à propriedade e à igualdade perante a lei), os direitos políticos (direito à participação do cidadão no governo da sociedade - voto) e os direitos sociais (direito à educação, ao trabalho, ao salário justo, à saúde e à aposentadoria), uma vez que a luta pelo direito à cidade ${ }^{17}$ fornece condições e objetivos a mais para a ação revolucionária (MARTINS, 2015). Para isso, os movimentos precisam permanentemente se reinventarem, buscar novas estratégias e romper com a cristalização, como sintetiza Santos (2001):

A organização é importante, como o instrumento de agregação e multiplicação de forças afins, mas separadas. Ela também pode constituir o meio de negociação necessário e vencer etapas e encontrar um novo patamar de resistência e de luta. Mas a obtenção de resultados, por mais compensadores que pareçam, não deve estimular a cristalização do movimento, nem encorajar a repetição de estratégias e táticas. Os movimentos organizados devem imitar o cotidiano das pessoas, cuja flexibilidade e adaptabilidade lhe asseguram um autêntico pragmatismo existencial e constituem a sua riqueza e fonte principal de veracidade (SANTOS, 2001, p. 134).

17 Para Lefebvre (2001) o direito à cidade está inserido aos direitos fundamentais do homem. 
Logo, é preciso ter clareza que as mudanças conjunturais sofridas pelos trabalhadores brasileiros nos últimos anos, como o acesso ao crédito, a melhoria de renda e o acesso ao consumo não garantiram a cidadania efetiva; deram apenas sinais de uma inserção precária (MARTINS,1997). Sentese, portanto, a necessidade de alimentar e direcionar a atuação dos movimentos para a liberdade e a emancipação humanas.

\section{CONSIDERAÇÕES FINAIS}

As mudanças provocadas pela aprovação do Estatuto da Cidade, pela criação do Ministério das Cidades e pela elaboração de políticas de habitação de interesse social e autogestionadas através da ascensão de governos com caráter popular a partir de 2002 estimularam o fundamento de intermediação e do diálogo entre os movimentos sociais sem-teto e o Estado. Entretanto, esta redefinição da participação política dos movimentos junto aos órgãos públicos trouxe uma série de questionamentos: minimizou-se a ação direta e transformadora, para supervalorizar o caráter do diálogo e intermediação com o Estado, ou seja, a figura de um representante do movimento no Conselho das Cidades e nas reuniões estratégicas com representantes das esferas municipal, estadual e federal, tornou-se essencial. Muitas vezes, alguns desses representantes mostram mais desenvoltura em realizar uma pauta de reivindicação, em sentar-se à mesa com representantes dos órgãos públicos, em leis e estatísticas conjunturais do que na mobilização das famílias para um ato promovido pelo movimento. Não que o diálogo não seja importante. Porém ele é um meio para a conquista e não o fim.

Esses motivos contribuíram para um período de refluxo dos movimentos sociais organizados e a indefinição (e crise) quanto à linha reivindicativa que alguns deles iriam adotar: "bater de frente" com o governo que promoveu a abertura destes canais? Instituir a ruptura e partir para a luta de reformas estruturais e não pontuais? A ruptura não "engordaria" setores conservadores e enfraqueceria a "esquerda"? 0 fato é que essas indefinições e a crise de representatividade fizeram ascender uma mobilização social diversa (de participantes e objetivos), como a verificada na jornada de junho de 2013 em todo o país, onde o objeto de críticas era muito mais difuso e com menos clareza (luta pela melhoria da saúde, transporte, segurança, educação, contra corrupção, etc.), mas não menos importante na luta urbana. Entretanto, o causador das mazelas sociais parece ter sido deixado em segundo plano, isto é, o sistema capitalista! Por outro lado, setores conservadores e reacionários começaram a ganhar destaque e representatividade no país, fruto de um contexto de descredibilidade política e da inoperância e do estado de "dormência" de setores populares organizados e das forças progressistas de "esquerda", ao passo que políticas mercadológicas, especialmente no contexto habitacional e de grandes obras urbanas ganharam destaque. 
Diante das dificuldades verificadas, o MLB ainda se vê na necessidade permanente de aprofundar as parcerias com prefeituras, governo estadual e federal e também com órgãos pertencentes a essas mesmas esferas, na busca de financiamentos públicos e bancários para construção das casas e obras de infraestrutura: esgotamentos sanitários, abertura de ruas, entre outros. Ademais, a despeito da combatividade dos movimentos e da existência de marcos legais favoráveis, o espaço entre esses dois setores ainda contém práticas sociais que se baseiam em relações clientelísticas e fisiologistas. Não se trata dos movimentos serem sectários com os meios de participação popular que foram criados, resultantes da mobilização histórica, nem tão pouco adotar um caráter burocrático e excessivamente intermediador. Há uma linha muito tênue entre essas duas instâncias a que o movimento deve estar atento: ter pessoas preparadas tecnicamente é tão importante quanto ter efetivas lideranças, ideologicamente concisas e claras, em consonância com as diretrizes do movimento.

Portanto, é preciso desenvolver ações insurgentes e realmente transformadoras, uma vez que a conjuntura social e política atualmente requer repensar a práxis, levantar bandeiras históricas e que foram minimizadas como a Reforma Urbana e a democratização do espaço urbano, compreendendo, logicamente o papel dos movimentos sociais sem-teto e até onde eles realmente podem e devem ocupar nas instâncias públicas, sem perder seu potencial de luta e de rompimento com o Status Quo. 


\section{REFERÊNCIAS}

BRASIL. Ministério das Cidades. Estatuto da cidade: guia para implementação pelos municípios e cidadãos. Câmara dos Deputados, coordenação de publicações. Brasília: 2001. Ministério das Cidades. Cadernos Mcidades: participação e controle social. Brasília: 2004.

BRASIL. Ministério das Cidades. Minha casa minha vida supera 1 milhão de moradias. Brasília, 29 de dezembro de 2010. Assessoria de comunicação. Disponível em: <http://www.cidades.gov.br/noticias/minh a-casa-minha-vida-supera-1-milhao-demoradias> Acesso em: 14 mar. 2017.

BRAGA, Ruy. A pulsão plebeia: trabalho, precariedade e rebeliões sociais. 1. ed. São Paulo: Alameda, 2015.

CARDOSO, Isabella Vitória Castilho Pimentel. 0 mundo do trabalho após a doutrina neoliberal no Brasil: privatização e flexibilização no contexto de crise econômica. Revista Pegada Eletrônica, vol. 17, n.1, p. 04-27, Julho/2016. Disponível em: <http://revista.fct.unesp.br/index.php/pega da/article/view/4403/3422>. Acesso em: 20 nov. 2016.

DE LA MORA, Luis. Produção social do habitat: Estratégia dos excluídos para a conquista do direito à cidade e à moradia, in: Novos Padrões de Acumulação Urbana na Produção do Habitat. Olhares Cruzados Brasil - França. Editora Universitária, UFPE, 2010.

FIX, Mariana. Financeirização e transformações recentes no circuito imobiliário no Brasil. Tese (Doutorado em Desenvolvimento Econômico) - Instituto de Economia/Unicamp, Campinas, 2011.

FUNDAÇÃO JOÃO PINHEIRO (FJP). Déficit habitacional no Brasil 2008. Convênio PNUD/Ministério das Cidades, Belo Horizonte, 2010.

FUNDAÇÃO JOÃO PINHEIRO (FJP). Centro de Estatística e Informações. Déficit habitacional municipal no Brasil. Belo Horizonte, 2013. Disponível em: Acesso em: 01 jun. 2016.

FREIRE, P. Pedagogia do Oprimido. 27ạ ed., RJ, Paz e Terra, 1987.
GRAZIA, G.D.; RODRIGUES, E. Uma alternativa para a gestão urbana: o Ministério das Cidades e seus desafios. Revista Rio de Janeiro, n.9, p. 11 a 21, jan./abr. 2003.

HARVEY, David. $O$ novo imperialismo. $2^{\mathrm{a}}$. Ed. São Paulo: Edições Loyola, 2005.

IBGE. Instituto Brasileiro de Geografia e Estatística. Cidades: Informações sobre os municípios brasileiros. Brasília: 2016. Disponível em: $<$ http://cidades.ibge.gov.br/xtras/home.ph p>. Acesso em: 11 dez. 2016.

LEFEBVRE, Henri. $O$ direito à cidade. São Paulo: Centauro Editora, 2001.

MARICATO, Erminia. Para entender a crise urbana. 1. Ed. São Paulo: Expressão Popular, 2015.

MARTINS, Rafael. A luta pelo direito à cidade: uma bandeira exógena ao marxismo? In: VII Colóquio Internacional Marx e Engels. Campinas: Unicamp, 2015.

MARTINS, José de Souza. Exclusão social e a nova desigualdade. São Paulo: Paulus, 1997.

MLB. Movimento de Luta nos Bairros, Vilas e Favelas. MLB, essa luta é pra valer! Disponível em: <http://www.mlbbrasil.org/our_team>. Acesso em: 08 fev. 2017.

SANTOS, Milton. Por uma outra Globalização: do pensamento único à consciência universal. Rio de Janeiro: Record, 2001.

SCHIAFFARINO, Júlia. Discussão sobre déficit habitacional no Recife. Diário de

Pernambuco, Recife, 10 jun. 2015.

Disponível em:

$<$ http://www.diariodepernambuco.com.br/ app/noticia/politica/2015/06/10/interna_ politica,580587/discussao-sobre-deficithabitacional-no-recife.shtml>. Acesso em: 22 mar. 2017.

SILVA, Cleiton Ferreira da. O Movimento de Luta nos Bairros, Vilas e Favelas (MLB) e a política de autogestão: análise de uma experiência no bairro da Iputinga, Recife-Pe. 2012. Dissertação (Mestrado em Geografia) - Universidade Federal da Paraíba, Recife, 2012. Disponível em: <http://www.geociencias.ufpb.br/posgrad/ dissertacoes/cleiton_ferreira.pdf $>$. Acesso em: 25 mar. 2017. 
Os grandes eventos esportivos e a dinâmica imobiliária e habitacional: a natureza e as contradições do Programa Minha Casa Minha Vida (PMCMV) em São Lourenço da Mata-Pe. Geographia Meridionalis. Pelotas, v. 02, n. 01, p. 38-62, Jan./Jun.2016.

SOUZA, M. L. de. $O$ desafio metropolitano: um estudo sobre a problemática sócio-espacial nas metrópoles brasileiras. Rio de Janeiro: Bertand Brasil, 2000.

. Com o Estado apesar do Estado, contra

o Estado: os movimentos urbanos e suas práticas espaciais, entre a luta institucional e a ação direta. Revista Cidades, v. 7, n. 11, pp. 13-47, 2010.

SOUZA, Maria Ângela de Almeida. Pensando a política nacional de habitação para a diversidade das famílias e dos municípios brasileiros. In: Bitoun, Jan; Miranda, Lívia (orgs). Desenvolvimento e Cidades no Brasil: contribuições para o debate sobre as Políticas Territoriais. Recife: FASE: Observatório das Metrópoles, 2009 